\title{
MICROSCOPY AND SPECTROSCOPY TOOLS FOR THE DESCRIPTION OF DELIGNIFICATION
}

\author{
H. M. HERNÁNDEZ-HERNÁNDEZ, ${ }^{* * *}$, J. J. CHANONA-PÉREZ, ${ }^{* * *}$ E. TERRÉS, ${ }^{* * * *}$ A. VEGA, ${ }^{* * * * *}$ \\ P. LIGERO, ${ }^{* * * * *}$ R. R. FARRERA-REBOLLO ${ }^{* * *}$ and S. VILLANUEVA* \\ ${ }^{*}$ CONACYT - Center for Research and Assistance in Technology and Design of the State of Jalisco A.C. \\ (CIATEJ), Guadalajara 44270, Jalisco, Mexico \\ ${ }^{* *}$ Center for Research and Development in Food Agrobiotechnology, C.P. 42162, San Agustín Tlaxiaca, \\ Hidalgo, Mexico \\ ${ }^{* * *}$ Department of Biochemistry Engineering, National School of Biological Sciences, National Polytechnic \\ Institute, Col. Santo Tomas C.P. 11340, Cd. de Mexico, Mexico \\ ${ }^{* * * * *}$ Mexican Petroleum Institute (IMP), Colonia San Bartolo Atepehuacan, \\ C.P. 07730, Cd. de Mexico, Mexico \\ Advanced Scientific Research Center (CICA), Department of Physical Chemistry and Chemical \\ Engineering, Coruña University, 15071 A Coruña, Spain \\ 『orresponding author: H. M. Hernández-Hernández,hhernandez@ciatej.mx
}

Received June 6, 2018

This work describes and evaluates the changes in agave fibres occurring during a green pulping process by microscopy and spectroscopy techniques, providing a comprehensive and quantitative view of the delignification of agave (Agave atrovirens) fibres. The effects of $80 \%$ acetic acid concentration and $0.3 \%$ hydrochloric acid concentration on pulp yield, kappa number and pulp viscosity were investigated over time. In order to study the influence of the Acetosolv treatment on the microstructure and chemical composition of agave fibres, spectroscopic and microstructural characterisations of selected pulps were performed at different points during the process.

Keywords: lignocellulosic material, confocal laser scanning microscopy, delignification, scanning electron microscopy, Raman spectroscopy

\section{INTRODUCTION}

Much agroindustrial waste comprises lignocellulosic materials, which are sources of important biomacromolecules, such as hemicelluloses, lignin and cellulose. ${ }^{1}$ The usage of such renewable materials opens a new sector in the chemical market, with potential positive impacts on mankind and the environment. ${ }^{2,3}$ Currently, many works focus on the usage of these materials in various applications, such as power, composite precursors, sources of bioactive compounds, new applications for cellulose, biodegradable plastics and new uses for lignin. ${ }^{4-6}$ Cellulose, the most abundant renewable natural polymer found in plants, is synthesised as structural microfibrils in the cell walls with different arrangements. ${ }^{7}$ Cellulose fibres are found in a wide variety of raw materials, including wood, leaves, seeds, fruits, bark and straws. Non-wood fibre sources are attractive due to their lower lignin content and their availability, given their shorter growing cycle. ${ }^{8}$ They have been widely used in a number of applications due to their favourable characteristics, such as renewability, biodegradability, high availability and sustainability.,, $9-12$ Agave is grown in the semi-desert areas of Mexico, mainly in Central Valley, Hidalgo, Puebla and the Tlaxcala states. ${ }^{13}$ Agave has been used for thousands of years in Mexico, with diverse applications as for the feeding, medication, clothing and construction. ${ }^{6}$ The lignocellulosic biomass of agricultural residues contains mainly cellulose (38\%), hemicellulose (32\%) and lignin (17\%) as major components, which can be converted into useful bioproducts, adopting the concept of "wealth from waste'. ${ }^{14}$ 
Agroindustrial lignocellulosic by-products are the most promising sources of cellulose and lignin. These include sugarcane bagasse, corn straw, palm-pressed mesocarp fibre, sisal, pineapple leaves etc. ${ }^{15-19}$ Agave waste may be an alternative source of cellulose and lignin. ${ }^{20,21}$ The leaves are cut to obtain the "piña" (pinecore) used for the making alcoholic beverages, like mezcal and tequila. ${ }^{6,22}$ Repeatedly harvested leaves or discarded reused leaves offer a potentially continuous supply of feedstock of lignocellulosic biomass. $^{6,22}$

Many processes and techniques have been developed in order to fractionate lignocellulosic biomass, among them, the Organosolv process uses organic acids. The list of possible green organic solvents used to fractionate biomass is extensive, for example, acetic acid, formic acid or ethanol, which are catalysed with strong acids (hydrochloric acid or sulfuric). ${ }^{1-3,23,24}$ The Organosolv process can 'clean' the pulp by two simultaneous mechanisms: delignification and solubilisation of the hemicelluloses; ${ }^{2}$ this process has been used for the treatment of lignocellulosic materials. ${ }^{1,3,25-27}$ Specifically, the Acetosolv process is used to fractionate biomass, taking advantage of the nature of acetic acid catalysed with hydrochloric acid. ${ }^{23,25}$

With minimal environmental impact, the Acetosolv process can fractionate the lignocellulosic material into cellulose (pulp fibres), acid lignin and monosaccharides. The acid delignification process breaks the $\alpha$-aryl ether bonds by means of hydrolysis. ${ }^{25,27}$

Agave waste may be an alternative source of cellulose and lignin with several applications in food, but the delignification mechanisms at the microstructural level have been scarcely studied on the fibre and the interest in agave fibres has been increasing. ${ }^{6,28-31}$ Thus, the physical and chemical mechanisms that occur during the Acetosolv treatment of agave fibres and the relationship between the chemical composition and the microstructure of fibres are evaluated by microscopy and spectroscopy.

\section{EXPERIMENTAL}

\section{Raw material and fibre isolation}

In order to obtain the fibre, leaves of agave (Agave atrovirens) waste were collected from a 5-7 years old plantation established in Mexico City, Mexico. Slices of agave leaves $(20 \times 20 \times 0.3 \mathrm{~cm})$ were dried in a convective dryer at $60{ }^{\circ} \mathrm{C}$ and an air flow rate of 3 $\mathrm{m} / \mathrm{s}^{32}$ Subsequently, the dry slices were milled (Blade mill, Moulinex, Selongey, France) and the fibres were separated through a mesh sieve no. 8 (US Standards). Fibres with a length of $2.36 \mathrm{~mm}$ or longer were stored in hermetic plastic bags at room temperature (20-22 ${ }^{\circ} \mathrm{C}$ ) until analysis; the final moisture content was $8.6 \%$.

\section{Raw material characterisation}

Residual lignin (T222 om88), moisture content (T412 om-11), solvent extractives (T204 cm-97), water solubility (T207 cm-99), ash (T211 om-02) and holocellulose (the chlorite method, T9 m-54) were determined according to the standards of the Technical Association of Pulp and Paper Industry (TAPPI). The content and distribution of monosaccharides in agave fibres was determined by HPLC (Aminex HPX-87H; Bio Rad, Philadelphia, Pennsylvania, USA).

\section{Acetosolv kinetics}

Acetosolv experiments were carried out in roundbottom flasks with a solid/liquid ratio of $1 / 10$. The aqueous solution with an $80 \%$ acetic acid concentration was heated to the boiling point, and when the target temperature was reached, a $0.3 \%$ hydrochloric acid concentration was added while stirring. The mixture was allowed to react for between 0 and 180 minutes. After the reaction, the pulp sample was filtered into medium-porosity glass crucibles and washed four times with acetic acid solutions. In the first of these washes, the quantity of the solution used was 2.5 times the dry weight of the agave fibres and, in the last two washes, the quantity of the solution was 5 times the dry weight. Finally, the pulp was repeatedly washed with distilled water until a neutral $\mathrm{pH}$ was acquired, and then the pulp was left to dry at room temperature. $^{33,34}$

\section{Pulp characterisation}

In order to study the kinetic changes, the pulp was characterised according to the Technical Association of Pulp and Paper Industry (TAPPI) standards. Moisture content was determined gravimetrically after drying the material at $105{ }^{\circ} \mathrm{C}$ (TAPPI T 412 om16). Pulp yield (PY) was determined gravimetrically and expressed as g dried pulp/100 g dry initial agave (\% dry basis) after oven drying until constant weight was achieved. TAPPI standards were applied to determine the kappa number (KN) of pulp (T236 om99) and the viscosity index or pulp viscosity (VIS) in a cupriethylenediamine solution (T230 om99). The delignification selectivity (SEL) of pulping was calculated as: ${ }^{35}$

Selectivity $=\frac{\text { Pulp viscosity }}{\text { Kappa number }}$

Spectroscopic and microstructural characterisation

To investigate the influence of the Acetosolv treatment on the microstructure and composition of the agave fibres, a spectroscopic and microstructural 
characterization of selected pulps was performed at different points during the process.

\section{Confocal laser scanning microscopy (CLSM)}

Confocal laser scanning microscopy permits to simultaneously monitor the changes on lignin and cellulose in the fibres during the Acetosolv process. Fibres or pulps were placed on a glass slide and observed under CLSM (LSM 710, Carl Zeiss, Germany). The presence of cellulose was examined during the pulping process by staining the fibres with calcofluor white M2R (fluorescent brightener 28 F3543, Sigma, USA) at $0.01 \%$ concentration for 5 minutes and then the fibres were dried at room temperature. Subsequently, the fibres were observed in the confocal microscope, using a diode laser (CW/pulsed) emitting at $405 \mathrm{~nm} .^{36}$ Lignin was monitored through its autofluorescence and the fibres were observed at $488 \mathrm{~nm}$ using an Argon laser. ${ }^{37,38}$ All images were acquired at $10 \mathrm{x}$ magnification in RGB color and stored in TIFF format at $512 \times 512$ pixels.

\section{Scanning electron microscopy (SEM)}

Microstructural changes occurring due to delignification were observed by SEM. Pulps were mounted in aluminum cylindrical sample holders provided with double sided carbon tape. The samples were observed with a scanning electron microscope (XL 30 ESEM, Philips, USA) at 300x and $25 \mathrm{kV}$.

\section{Raman spectroscopy}

Raman spectroscopy measurements were performed using a LabRam HR 800 (Horiba Jobin Yvon; Miyanohigashi, Kyoto, Japan) coupled to an Olympus BX 41 microscope with a 100x objective. Raman spectra were recorded using a 600 lines $/ \mathrm{mm}$ grating and a $785 \mathrm{~nm}$ emission laser. Spectral resolution was approximately $2 \mathrm{~cm}^{-1}$. The measurements were conducted using wavenumbers from $100 \mathrm{~cm}^{-1}$ to $3060 \mathrm{~cm}^{-1}\left(20{ }^{\circ} \mathrm{C}\right)$. The spectra were recorded using an exposure time of 8-10 s. The spectra acquisitions were managed by the LabSpec software (Horiba JobinYvon) and edited using the freeware Spekwin 32 program. ${ }^{39}$

\section{X-ray diffraction (XRD)}

X-ray diffraction analysis was conducted using a Rikagu MiniFlex 600 diffractometer (Japan), with $\mathrm{CuK} \alpha$ radiation source, at $40 \mathrm{kV}$ and $15 \mathrm{~mA}$. Scans were obtained from 3 to 60 degrees $2 \theta$ in 0.01 increments for 3 seconds per step. CrI was calculated as: $\left(\mathrm{I}_{002}-\mathrm{I}_{\mathrm{am}}\right) /\left(\mathrm{I}_{002}\right)$ after subtraction of the background signal measured without cellulose. ${ }^{40-44}$ A peak fitting program (PeakFit v.4.12) was used, assuming Lorentz functions for each peak and a broad peak at around $21.5^{\circ}$ assigned to the amorphous contribution. ${ }^{43,45}$ Iterations were repeated until the maximum $\mathrm{F}$ number was obtained. In all the cases, the $F$ number was $>5000$, corresponding to a $\mathrm{R}^{2}$ value of 0.993 .

\section{RESULTS AND DISCUSSION Chemical composition of agave fibres}

The chemical composition of agave leaves is shown in Table 1. It can be seen that the ash content $(3.5 \%)$ is within the range $(2.1-8.0 \%)$ previously reported for fibre from raw cores. ${ }^{46-48}$ Agave leaves contain $56-60 \%$ potentially fermentable sugars, over half of which are present in a soluble fraction. In the case of Agave atrovirens, the hot water extract content $(43.5 \%)$ was higher than the one reported for untreated leaves of Agave americana (29.1\%) and Agave tequilana $(15.3 \%) .{ }^{49}$ On the other hand, the acid insoluble lignin content was smaller than the one reported for untreated agave fibres $-2.1 \%^{50}$ and $2.72 \%,{ }^{51}$ pineapple $-3.46 \%,{ }^{52}$ and leaf $-4.9 \% .^{22}$ The holocellulose content (cellulose plus hemicelluloses) obtained in the present study $(42.9 \%)$ is lower than the one reported for sisal leaves $(49.6 \%)$ without treatment. ${ }^{22,47,48}$ As for the distribution of monosaccharides in agave leaves, glucose was the majority sugar, whereas the noncellulosic sugar content (roughly hemicelluloses) reached a value of $11.9 \%$. This content is similar to that reported for untreated leaves of $A$. americana $(9.3 \%)$ and A. tequilana $(9.7 \%){ }^{49}$

\section{Acetosolv kinetics}

Figure 1 presents the response variables of the pulping process (PY, KN and VIS), which display an exponential behaviour. Figures 1A, 1B and 1C present the kinetics of delignification in the Acetosolv process under the aforementioned conditions with exponential decay behaviour. For $\mathrm{KN}$ and PY, a first stage can be seen during the first 30 minutes, corresponding to the rapid delignification phase that is explained by the easy removal of the surface lignin in the agave fibre; the second stage covers the lapse from the $30 \mathrm{~min}$ to $180 \mathrm{~min}$; here, both $\mathrm{KN}$ and PY decreased at a lower speed compared to the first stage, which may be due to the extraction of interfibrillar lignin from the agave fibres (Fig. 1A and 1B). For the VIS, the first stage corresponds to the interval between 0 min and $40 \mathrm{~min}$, while the second stage covers the lapse from 60 to $180 \mathrm{~min}$. These stages of delignification were similar to those reported for the pulping of Eucalyptus globulus, ${ }^{53}$ and several hardwoods using a Kraft process. ${ }^{54}$ Table 2 presents the results of the pulping process. Selectivity is the ratio between viscosity and kappa number, thus a high delignification selectivity indicates a high degree of delignification with low cellulose degradation. ${ }^{35,55}$ 


\section{H. M. HERNÁNDEZ-HERNÁNDEZ et al.}

The results of Table 2 indicate better delignification selectivity of pulping at 30 (SEL = 95.5) and 40 (SEL = 102.2) $\mathrm{min}$; however, if the optimal time of delignification is exceeded, selectivity decreases, which was confirmed by previous publications. ${ }^{55,56}$ In general, organosolv pulping has a low effect on carbohydrate degradation (cellulose, in particular) and has good selectivity in the delignification reaction. The selectivity values of this work are higher than those reported for the Kraft process (69.2), the kraft process with anthraquinone (72.8), the kraft process with sodium xylenesulfonate pretreatment (83.4), the kraft process with sodium xylenesulfonate pretreatment and addition of anthraquinone (85.3), ${ }^{35}$ and is well above the values for processes involving the use of microorganisms (15), ${ }^{57}$ or processes involving ethanol and water (12-16). ${ }^{58}$

\section{Microstructural changes due to pulping}

In order to describe and evaluate the changes in agave fibres during the Acetosolv process, these fibres were analysed by means of SEM and CLSM (Fig. 2). The fluorescence of cellulose and lignin by CLSM is similar to that reported in previous studies, ${ }^{6,28}$ in which it is assumed that the autofluorescence of timber materials is mainly due to the lignin content and its intensity is directly proportional to its concentration. SEM allows observing the agave fibre as a structure assembled in several layers, similar to the one reported by other authors for $A$. americana and $A$. tequilana Weber, blue variety. ${ }^{36,46,59}$

Table 1

Chemical composition of agave leaves

\begin{tabular}{lc}
\hline Component & Content (\% dry basis) \\
\hline Ash & $3.5 \pm 0.16$ \\
Hexane extracts & $3.2 \pm 0.13$ \\
Hot water extracts & $43.5 \pm 1.32$ \\
Acid insoluble lignin & $1.9 \pm 0.36$ \\
Holocellulose & $42.9 \pm 0.90$ \\
Monosaccharides (by HPLC) & \\
$\quad$ Glucose & $35.7 \pm 0.81$ \\
Xylose + galactose + mannose & $10.4 \pm 1.11$ \\
Arabinose & $1.5 \pm 0.55$ \\
\hline
\end{tabular}
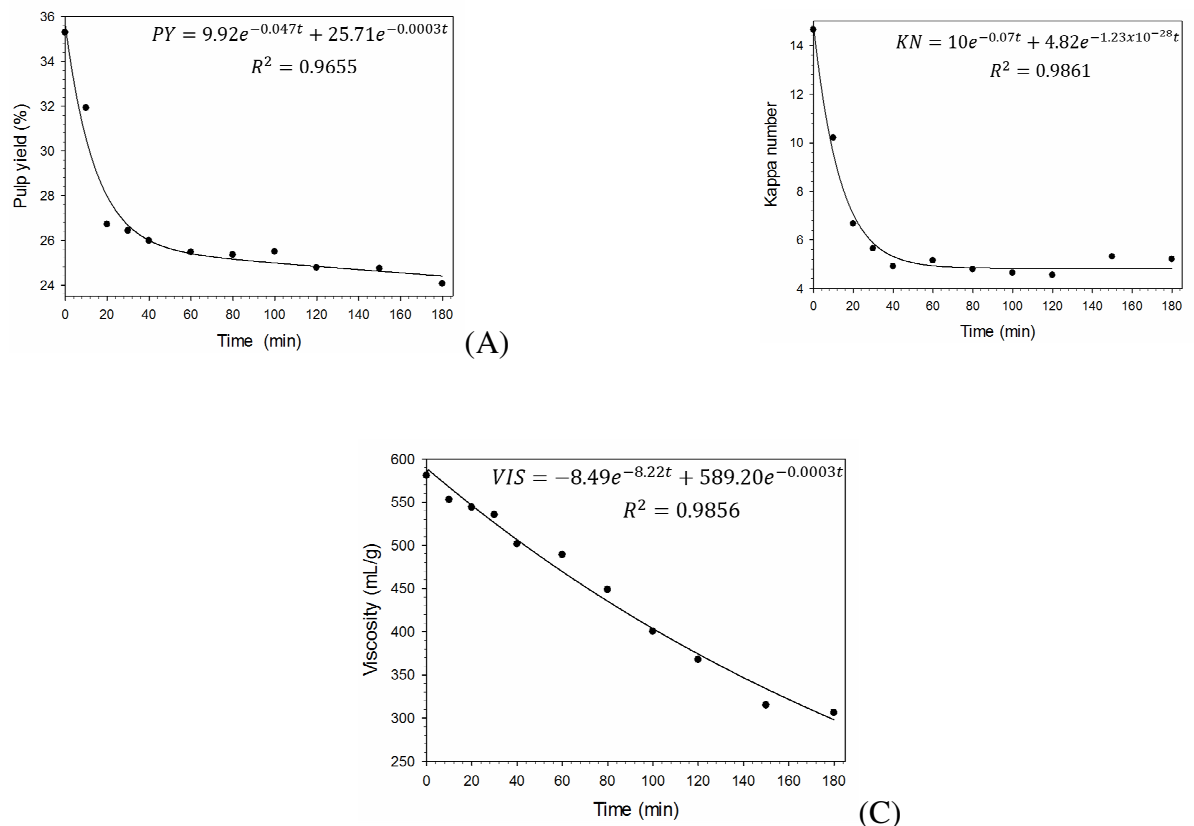

(C)

Figure 1: Acetosolv process kinetics: (A) pulp yield, (B) Kappa number and (C) viscosity index 
Delignification

Table 2

Response variables as a function of duration of Acetosolv process

\begin{tabular}{ccccc}
\hline $\begin{array}{c}\text { Time } \\
\text { (minutes) }\end{array}$ & $\begin{array}{c}\text { PY } \\
(\%)\end{array}$ & KN & $\begin{array}{c}\text { VIS } \\
(\mathrm{mL} / \mathrm{g})\end{array}$ & SEL \\
\hline 0 & 35.3 & 14.6 & 581 & 39.8 \\
10 & 31.9 & 10.2 & 553 & 54.2 \\
20 & 26.7 & 6.7 & 544 & 81.2 \\
30 & 26.4 & 5.6 & 535 & 95.5 \\
40 & 26.0 & 4.9 & 501 & 102.2 \\
60 & 25.5 & 5.1 & 489 & 95.9 \\
80 & 25.4 & 4.8 & 449 & 93.5 \\
100 & 25.5 & 4.6 & 400 & 87.0 \\
120 & 24.8 & 4.6 & 368 & 80.0 \\
150 & 24.7 & 5.3 & 315 & 59.4 \\
180 & 24.1 & 5.2 & 306 & 58.8 \\
\hline
\end{tabular}

At the beginning $(0 \mathrm{~min})$, the fluorescence of the cellulose was the lowest (Fig. 2F), and the autofluorescence of the lignin was very intense (CLSM), which corresponds to the lignified fibres with lower cellulose purification. Meanwhile, the SEM image illustrates the structural arrangement of the fibre bundle without damage (Fig. 2A).

The reaction continued until 30 minutes, when the fluorescence of the cellulose was the most intense (Fig. 3G), which indicates a purified fibre. Therefore, the autofluorescence of the lignin only appeared in small areas of the fibre in the CLSM image. In the SEM image (Fig. 2B), the defibrated fibre bundle can be observed; at $30 \mathrm{~min}$, lignin dissolution occurred. This can be considered the optimal cellulose purification time, which correlates with the maximum value of CrI (Table 4). The time matches the inflection point of the two stages in $\mathrm{KN}$ and PY (Fig. 1A and 1B), which agrees with the results of other studies, where the rapid dissolution of materials occurred in the first minutes of the process. ${ }^{2,60-62}$

As regards the $60 \mathrm{~min}$ duration of the reaction, the surface of the pulp is covered by lignin, indicating the condensation and reprecipitation of lignin on the surface (Fig. 2H). Also, in the SEM image (Fig. 2C), damage in the structure of the fibre can be observed.

After 100 minutes of reaction, the fibres demonstrated an increase in lignin autofluorescence (Fig. 2I). In the SEM image, compaction and damage of the fibres is observed (Fig. 2D). This behaviour is intensified after 180 minutes of reaction (Fig. 2E and 2J).

\section{Raman spectroscopy}

The pulps (treated fibres) of the Acetosolv process were analysed by FT-Raman spectroscopy to provide a better understanding of the chemical changes occurring during the delignification of the fibres. Figure 3 presents the spectra of the five pulps considered $(0,30,60$, 100 and $180 \mathrm{~min}$ ) and the untreated agave fibres after the baseline correction and the normalization of the area. Table 3 illustrates how some of the characteristics of composition can be distinguished, according to the assignments of Raman bands provided in previously published works. ${ }^{63-66}$ It can be seen that strong bands lack intensity or have low intensity.

At $1,601 \mathrm{~cm}^{-1}$, an intense band of lignin, which is attributed to the symmetric stretching of carbon-carbon double bonds, is absent in the spectra of 30 and 60 min pulps (Fig. 3), which indicates the absence of lignin in the fibres (Fig. $3)$. Another strong lignin band $\left(1,660 \mathrm{~cm}^{-1}, \mathrm{C}=\mathrm{O}\right.$ and $\mathrm{C}=\mathrm{C}$, which is attributed to the stretching of the coniferyl and sinapyl alcohols, as well as aldehyde-like structures) is absent in the spectra of all the pulps, whereas the lignin bands that are produced in the regions of 560-790 and 1,508$1,658 \mathrm{~cm}^{-1}$ demonstrate slight intensities. Existing bands are due to vibrations in the carbohydrate structures. The bands at 1,096 and $1,122 \mathrm{~cm}^{-1}$ (due to several stretches of glycosidic bonds) are present in the pulp (treated fibres) with greater intensity after $100 \mathrm{~min}$. This could be interpreted as an increase in the delignification and condensation of lignin in the pulp after this period, with the subsequent deterioration of the cellulose (probably, hydrolytic) as the process conditions become more severe, which leads to the breaking of some glycosidic bonds with a concomitant decrease in the intensity of the bands generated in this part of the carbohydrate chain. 


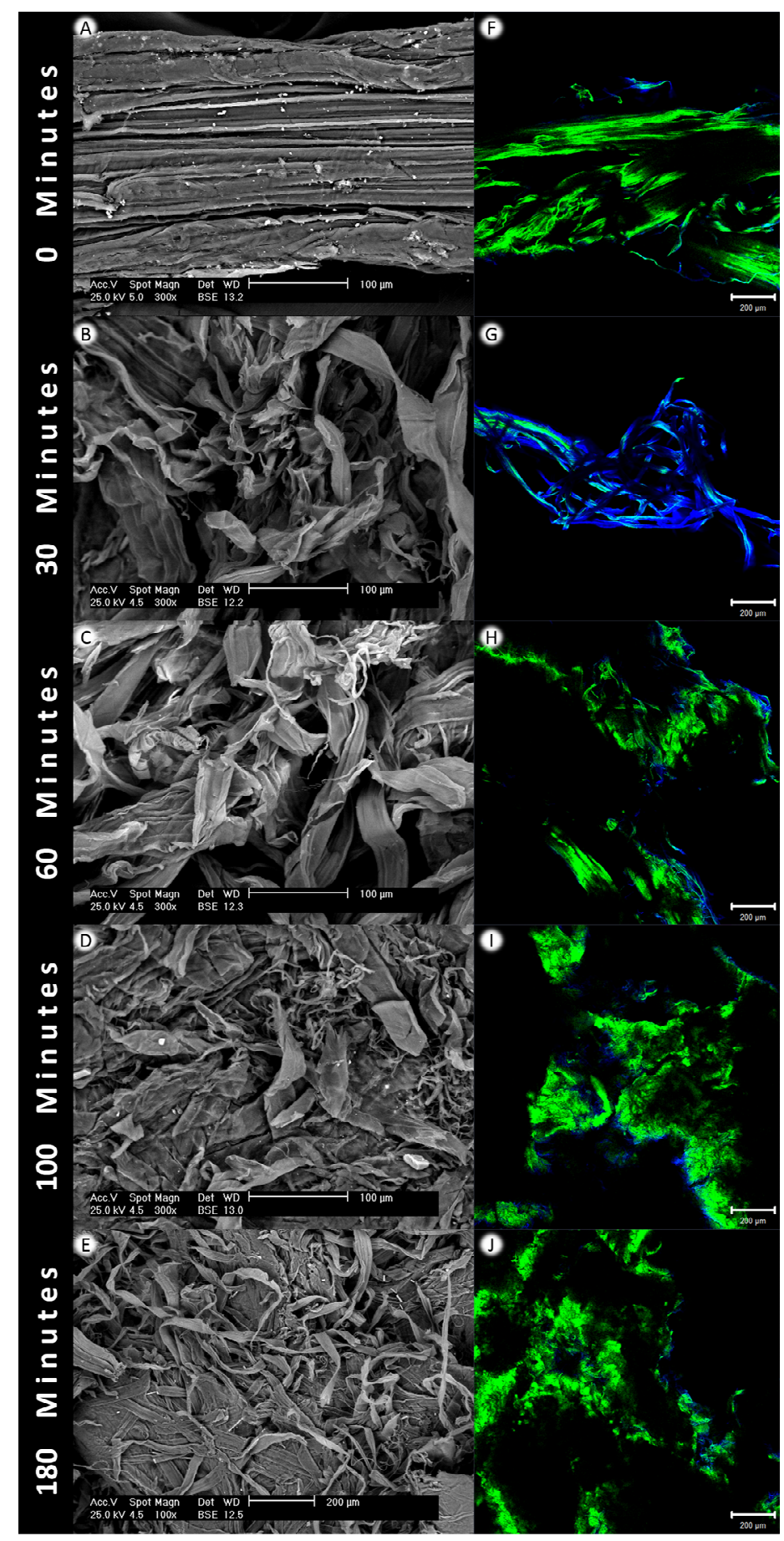

Figure 2: SEM images (A, B, C, D and E) and CLSM images (F, G, H, I and J) of agave fibre at different pulping time points $(0,30,60,100$ and $1800 \mathrm{~min})$; (green colour corresponds to lignin and blue colour to cellulose) 
Table 3

Assignment of Raman bands in average spectra of agave fibres

\begin{tabular}{|c|c|c|}
\hline Raman shift $\left(\mathrm{cm}^{-1}\right)$ & Component & Assignment \\
\hline 2945 & Lignin + Glucomannan & $\mathrm{C}-\mathrm{H}$ asymmetric stretching in $\mathrm{OCH}_{3}$ \\
\hline 2897 & Cellulose & C-H stretching in $\mathrm{R} 3 \mathrm{C}-\mathrm{H}$ \\
\hline 1736 & Hemicellulose & Carbonyl stretching vibrations of hemicelluloses \\
\hline 1658 & Lignin & Stretching of conifer alcohol + stretching $\mathrm{C}=\mathrm{O}$ in coniferaldehyde \\
\hline 1620 & Lignin & $\mathrm{C}=\mathrm{C}$ stretching of coniferaldehyde/sinapaldehyde \\
\hline 1601 & Lignin & Aromatic ring symmetric stretching \\
\hline 1480 & Cellulose & $\mathrm{CH}_{2}$ bending \\
\hline 1465 & Cellulose & $\mathrm{CH}_{2}$ bending (scissors), $\mathrm{COH}$ bending in alcohols $1^{\circ}$ and $2^{\circ}$ \\
\hline 1423 & Lignin & $\mathrm{O}-\mathrm{CH}_{3}$ bending, ring stretching \\
\hline 1378 & Cellulose & $-\mathrm{CH}_{3}$ bending, ring stretching \\
\hline 1330 & Lignin & Aromatic ring breathing, $\mathrm{CO}$ stretching \\
\hline 1270 & Lignin & Aryl-O in aryl-OH and aryl $\mathrm{O}-\mathrm{CH}_{3}$, vibration of guaiacyl ring with $\mathrm{C}=\mathrm{O}$ group \\
\hline 1130 & Lignin & Vibration of conyferaldehyde/sinapaldehyde \\
\hline 1121 & Cellulose + Xylan + Glucomannan & COC symmetric glycosidic stretching, ring breathing, skeletal vibration \\
\hline 1098 & Cellulose + Xylan + Glucomannan & COC asymmetric glycosidic stretching, ring breathing, skeletal vibration \\
\hline 1037 & Cellulose & $\mathrm{CC}, \mathrm{CO}$ stretching. Alcohol $2^{\circ}$ \\
\hline 896 & Cellulose & HCC and HCO bending, cluster of peaks, primary methine bending \\
\hline 786 & Lignin & Skeletal deformation \\
\hline 730 & Lignin & Aromatic ring twisting \\
\hline 634 & Lignin & Ring deformation \\
\hline 595 & Lignin & Skeletal deformation \\
\hline 560 & Lignin & Skeletal deformation \\
\hline 520 & Cellulose & COC bending, glyc. links/CCC ring deformation \\
\hline 458 & Cellulose & Bending CCO, CCC, ring deformation, skeletal bending \\
\hline 435 & Cellulose & Bending $\mathrm{CCO}, \mathrm{CCC}$, ring deformation \\
\hline 378 & Cellulose & Symmetric bending CC, ring deformation \\
\hline
\end{tabular}




\section{H. M. HERNÁNDEZ-HERNÁNDEZ et al.}

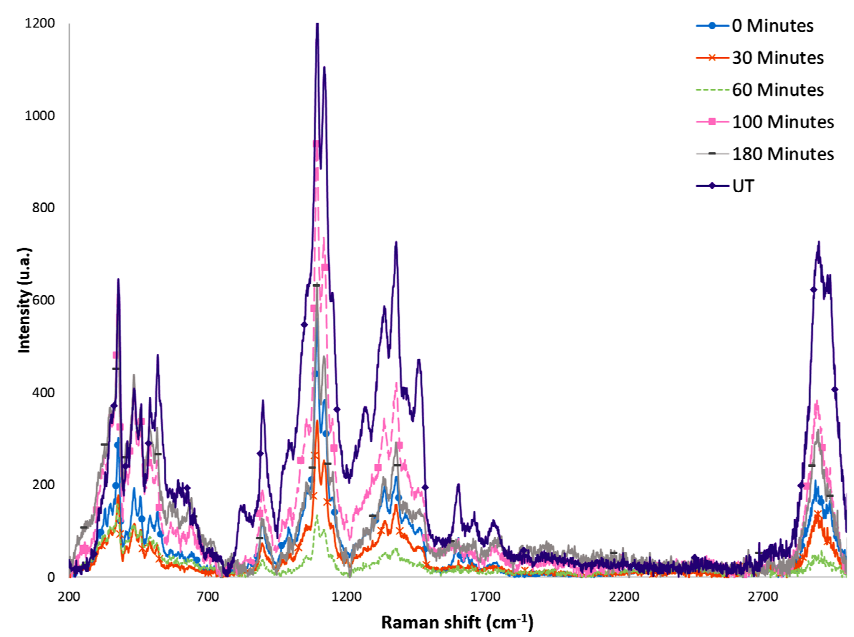

Figure 3: FT-Raman spectra of untreated agave fibres and pulps treated for different time periods

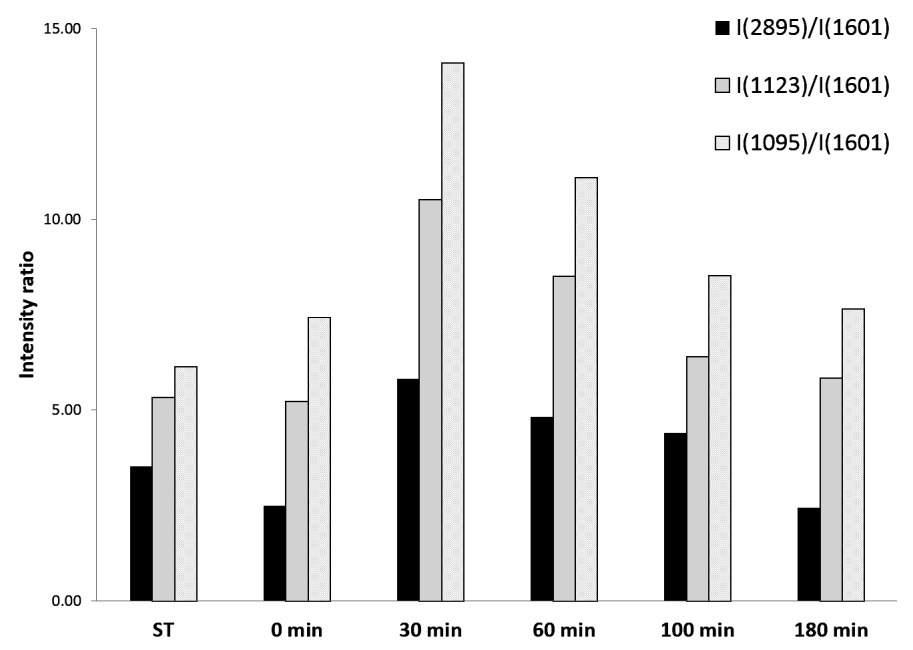

Figure 4: Comparison of intensity ratios of selected representative Raman bands of agave fibres subjected to Acetosolv pulping for different time periods

The characteristic cellulose bands $(2,895$, 1,123 and $1,095 \mathrm{~cm}^{-1}$ ) reflect an enrichment of the solid cellulose. The previous discussion can be applied to almost all of these bands since they maintain the order of the intensities. Other bands are associated with symmetrical bending (380, $435,460 \mathrm{~cm}^{-1}$ ) and several vibrations of pitch (wagging) and bending $\left(1,380 \mathrm{~cm}^{-1}\right)$ in the rings of glycopyranose.

Figure 4 presents a comparison between the ratios of the intensities of the characteristic bands of representative carbohydrates $(1,095,1,123$ and $2,895 \mathrm{~cm}^{-1}$ ) and the strongest band of lignin $\left(1,601 \mathrm{~cm}^{-1}\right)$. The pulps reflect the characteristics of carbohydrates with the increase in the experimental variables, up to 30 minutes, because from this point, the degradation of the sugar chains is predominant, which decreases all the intensity relationships.

\section{X-ray diffraction analysis}

Using the most common procedure for the measurement of the $\mathrm{CrI},{ }^{40}$ namely, the peak height, the CrI was calculated and the data obtained are presented in Table 4. Figure 5 illustrates the X-ray diffractograms of the untreated agave fibres and those subjected to the Acetosolv pulping process for different time periods. The effect of pulping duration on the pulps was evidenced after 60 minutes of reaction, when the crystallinity is diminished in the X-ray diffractograms, which is evident in the difference in the relative intensities of the peaks analysed. The CrI calculated from the X-ray data 
determining these peaks is given in Table 4, where $\mathrm{CrI}$ increases in the first 30 minutes of the treatment; the highest crystallinity value was obtained for the 30 min pulping. XRD analysis reveals that treated agave fibres seem to have undergone some polymorphic changes, upon the Acetosolv treatment, on the principal diffraction planes, $101\left(2 \theta=15.4-17.7^{\circ}\right), 002(2 \theta=22.0$ - $\left.23.4^{\circ}\right)$ and $040\left(2 \theta=34.1-35.9^{\circ}\right)$, which gradually turned to minimum values over treatment time. However, the diffractograms do not demonstrate a clear division of the bands (especially, plane 002), which implies that cellulose I (native) was converted to cellulose II.

Table 4

Crystalline index of treated agave leaves determined by Segal's method

\begin{tabular}{lc}
\hline \multirow{2}{*}{ Pulp } & Crystalline index (CrI, \%) \\
\cline { 2 - 2 } UT & Peak height \\
0 minutes & 43.2 \\
30 minutes & 61.9 \\
60 minutes & 70.3 \\
100 minutes & 69.5 \\
180 minutes & 68.6 \\
\hline
\end{tabular}

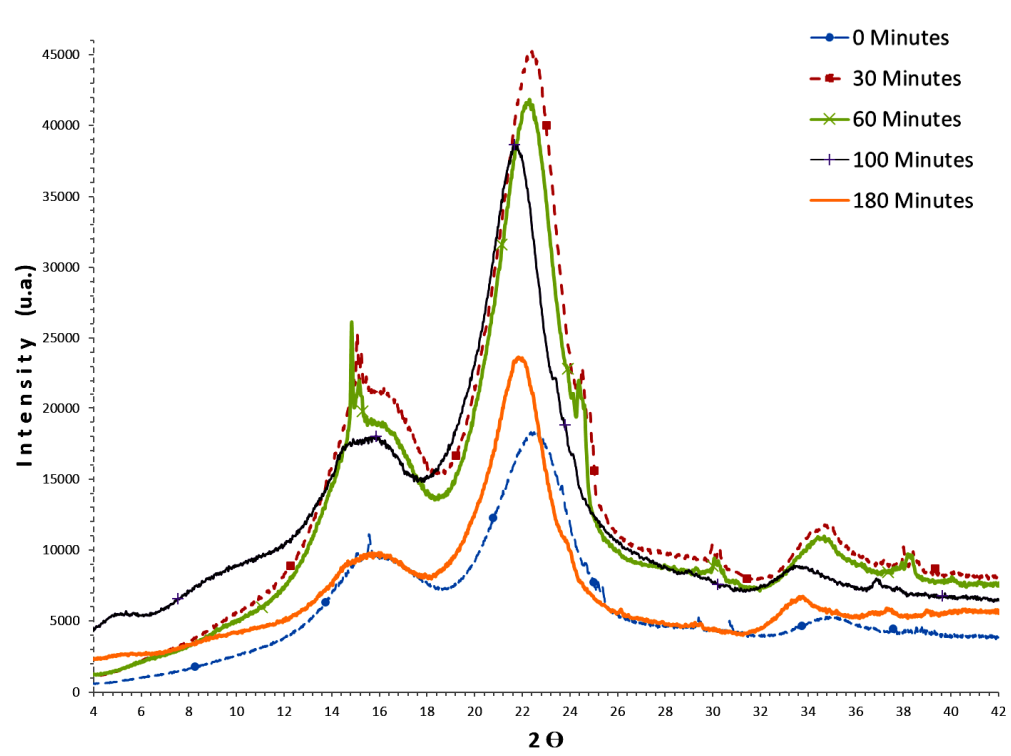

Figure 5: X-ray diffractograms of pulp treated for different process time periods and untreated agave pulp

\section{CONCLUSION}

This work describes the changes occurring in agave fibres during a green pulping process and evaluates them by microscopy and spectroscopy techniques, providing a comprehensive quantitative view of the phenomenon occurring during the delignification of agave fibres. The delignification process occurs in two stages: the first one corresponds to the superficial delignification of the fibre $(0-30 \mathrm{~min})$, and the second stage corresponds to the removal interfibrillar lignin of the fibre, which is corroborated by the disappearance of the characteristic band of lignin in Raman spectra and the increase in the index of crystallinity. The microscopy techniques applied in this work were useful to monitor the microstructural changes occurring during the pulping processing, while FT-Raman spectroscopy confirmed the data obtained by chemical analysis about pulp purity and the efficiency of the delignification process in terms of cellulose preservation in the fibre.

\section{REFERENCES}

H.-L. Li, D. She, P. Peng, Q. Xu, J. Liu et al., Cellulose Chem. Technol., 51, 433 (2017), 
http://www.cellulosechemtechnol.ro/pdf/CCT56(2017)/p.433-445.pdf

2 A. de Vega, P. Ligero, A. De Vega and P. Ligero, Ind. Crop. Prod., 97, 252 (2017), https://doi.org/10.1016/j.indcrop.2016.12.021

3 N. F. Souza, J. A. Pinheiro, A. I. S. Brígida, J. P. S. Morais, M. M. de Souza Filho et al., Ind. Crop. Prod., 94, 480 (2016),

https://doi.org/10.1016/j.indcrop.2016.09.012

4 T. Virtanen, K. Svedström, S. Andersson, L. Tervala, M. Torkkeli et al., Cellulose, 19, 219 (2012), https://doi.org/10.1007/s10570-011-9636-6

5 R. Moriana, F. Vilaplana and M. Ek, Cellulose, 22, 3409 (2015), https://doi.org/10.1007/s10570-0150738-4

6 H. M. Hernández-Hernández, J. J. Chanona-Pérez, A. Vega, P. Ligero, J. A. Mendoza-Pérez et al., Ind. Crop. $\quad$ Prod., $\quad 86, \quad 163 \quad$ (2016), https://doi.org/10.1016/j.indcrop.2016.03.043

7 M. George, W. Shen, K. Sharma, C. Montemagno and M. George, Cellulose Chem. Technol., 51, 681 (2017),

http://www.cellulosechemtechnol.ro/pdf/CCT78(2017)/p.681-691.pdf

8 N. Marin, A. C. Puitel, A.-M. Chesca and D. Gavrilescu, Cellulose Chem. Technol., 51, 745 (2017), http://www.cellulosechemtechnol.ro/pdf/CCT78(2017)/p.745-753.pdf

9 R. C. Saxena, D. K. Adhikari and H. B. Goyal, Renew. Sustain. Energ. Rev., 13, 167 (2009), https://doi.org/10.1016/j.rser.2007.07.011

10 T. Joffre, O. Girlanda, F. Forsberg, F. Sahlén, M. Sjödahl et al., Cellulose, 22, 2993 (2015), https://doi.org/10.1007/s10570-015-0727-7

11 M. Jonoobi, R. Oladi, Y. Davoudpour, K. Oksman, A. Dufresne et al., Cellulose, 22, 935 (2015), https://doi.org/10.1007/s10570-015-0551-0

12 A. L. de Lemos, C. J. Mauss and R. M. C. Santana, Cellulose Chem. Technol., 51, 711 (2017), http://www.cellulosechemtechnol.ro/pdf/CCT78(2017)/p.711-718.pdf

13 A. Z. M. Salem, N. T. Valdez, O. A. Olafadehan, M. M. Y. Elghandour, A. Barbabosa Pliego et al., J. Equine Vet. Sci., 48, 103 (2017)., DOI: 10.1016/j.jevs.2016.08.012

14 C. M. Y. Huang, P. X. Chia, C. S. S. Lim, J. Q. Nai, D. Y. Ding et al., Cellulose Chem. Technol., 51, 665 (2017), http://www.cellulosechemtechnol.ro/pdf/ CCT7-8(2017)/p.665-672.pdf

15 B. V. M. Rodrigues, E. C. Ramires, R. P. O. Santos and E. Frollini, J. Appl. Polym. Sci., 132, 16 (2015), https://doi.org/10.1002/app.41826

16 A. Mandal and D. Chakrabarty, J. Ind. Eng. Chem., 20, $462 \quad$ (2014), https://doi.org/10.1016/j.jiec.2013.05.003

17 C. J. Huntley, K. D. Crews and M. L. Curry, Int. J. Polym. Sci., 2015, 1 (2015).

18 B. Deepa, E. Abraham, N. Cordeiro, M. Mozetic, A. P. Mathew et al., Cellulose, 22, 1075 (2015), doi: 10.1007/s10570-015-0554-x.

19 D. M. do Nascimento, J. S. Almeida, M. do S. Vale, R. C. Leitão, C. R. Muniz et al., Ind. Crop. Prod., $\quad$ 93, $66 \quad$ (2016), https://doi.org/10.1016/j.indcrop.2015.12.078

20 J. R. González-López, J. F. Ramos-Lara, A. Zaldivar-Cadena, L. Chávez-Guerrero, R. X. Magallanes-Rivera et al., Fuel Process. Technol., 133, 35 (2015)

https://doi.org/10.1016/j.fuproc.2014.12.041

21 J. R. Mielenz, M. Rodriguez, O. A. Thompson, X. Yang and H. Yin, Biotechnol. Biofuels, 8, 79 (2015).

22 S. C. Davis and S. P. Long, in "Industrial Crops: Breeding for BioEnergy and Bioproducts", New York, Springer, 2015, pp. 335-349.

23 G. Iñiguez-Covarrubias, R. Díaz-Teres, R. SanjuanDueñas, J. Anzaldo-Hernández and R. M. Rowell, Bioresour. Technol., 77, $101 \quad$ (2001), https://doi.org/10.1016/S0960-8524(00)00167-X

24 A. Ferrer, A. Vega, A. Rodríguez and L. Jiménez, Bioresour. Technol., 132, 115 (2013), doi: 10.1016/j.biortech.2012.12.189

25 Q. Tu, S. Fu, H. Zhan, X. Chai and L. A. Lucia, J. Agric. Food Chem., 56, 3097 (2008), doi: 10.1021/jf0729659

26 V. P. Soudham, D. Rodriguez, G. J. M. Rocha, M. J. Taherzadeh and C. Martin, For. Stud. China, 13, 64 (2011).

27 M. Zhang, K. S. Hui, G. Gong, K. N. Hui and L. Liu, Cellulose Chem. Technol., 51, 425 (2017), http://www.cellulosechemtechnol.ro/pdf/CCT5-

6(2017)/p.425-431.pdf

28 W. Wanrosli, I. Mazlan, K. Law and R. Nasrullah, Maderas. Cienc. Tecnol., 13, 193 (2011), http://dx.doi.org/10.4067/S0718-221X2011000200007

${ }_{29}$ J. F. Ma, G. H. Yang, J. Z. Mao and F. Xu, Ind. Crop. $\quad$ Prod., 33, $358 \quad$ (2011), https://doi.org/10.1016/j.indcrop.2010.11.009

30 Q. Yang and X. Pan, Bioresour. Technol., 126, 336 (2012), doi: 10.1016/j.biortech.2012.10.018.

31 M. F. Li, S. Yang and R. C. Sun, Bioresour. Technol., 200, 971 (2016), doi: 10.1016/j.biortech.2015.10.004

32 H. M. Hernández-Hernández, J. J. Chanona-Pérez, A. Vega, P. Ligero, R. R. Farrera-Rebollo et al., Microsc. Microanal., 22, 5 (2016), https://doi.org/10.1017/S1431927616011818

33 C. Gumeta-Chávez, J. J. Chanona-Pérez, J. A. Mendoza-Pérez, E. Terrés-Rojas, V. Garibay-Febles et al., Dry. Technol., 29, 612 (2011), DOI: 10.1080/07373937.2010.514380

34 P. Ligero, J. J. Villaverde, A. Vega and M. Bao, Ind. Crop. Prod., 25, $294 \quad$ (2007), https://doi.org/10.1016/j.indcrop.2006.12.009 35 P. Ligero, A. Vega and M. Bao, Ind. Crop. Prod., 21, 235 (2005), https://doi.org/10.1016/j.indcrop.2004.04.006 36 A. Bessadok, D. Langevin, F. Gouanvé, C. Chappey, S. Roudesli et al., Carbohyd. Polym., 76, 74 
(2009), https://doi.org/10.1016/j.carbpol.2008.09.033

37 F. Xu, X. C. Zhong, R. C. Sun and Q. Lu, Ind.

Crop. Prod., 24, 186 (2006), https://doi.org/10.1016/j.indcrop.2006.04.002

38 K. H. Lee, S. G. Wi, A. P. Singh and Y. S. Kim, $J$. Wood Sci., $\quad 50, \quad 281 \quad$ (2004), https://doi.org/10.1007/s10086-003-0558-2

39 Z. Zhang, J. Ma, Z. Ji and F. Xu, Microsc. Microanal., $\quad 18, \quad 1459 \quad$ (2012), doi: 10.1017/S1431927612013451

40 Y. Hu, L. Tang, Q. Lu, S. Wang, X. Chen and B. Huang, Cellulose, 21, 1611 (2014), DOI: 10.1007/s10570-014-0236-0

41 D. Yang, L. X. Zhong, T. Q. Yuan, X. W. Peng and R. C. Sun, Ind. Crop. Prod., 43, 141 (2013), https://doi.org/10.1016/j.indcrop.2012.07.024

${ }^{42}$ S. Park, J. O. Baker, M. E. Himmel, P. A. Parilla and D. K. Johnson, Biotechnol. Biofuels, 3, 10 (2010), doi: 10.1186/1754-6834-3-10

43 C. Driemeier, M. T. B. Pimenta, G. J. M. Rocha, M. M. Oliveira, D. B. Mello et al., Cellulose, 18, 1509 (2011), https://doi.org/10.1007/s10570-011-9592-1

44 L. Segal, J. J. Creely, J. A. E. Martin and C. M. M. Conrad, Text. Res. J., 29, 786 (1959), https://doi.org/10.1177/004051755902901003

45 E. L. Hult, T. Iversen and J. Sugiyama, Cellulose, 10 103 (2003), https://doi.org/10.1023/A:1024080700873

46 C. J. Garvey, I. H. Parker and G. P. Simon, Macromol. Chem. Phys., 206, 1568 (2005).

J. He, S. Cui and S. Wang, J. Appl. Polym. Sci., 107, 1029 (2008), https://doi.org/10.1002/app.27061

47 S. Kestur, T. H. S. Flores-Sahagun, L. P. Dos Santos, J. Dos Santos, I. Mazzaro et al., Composite part A, 45, $153 \quad$ (2013), https://doi.org/10.1016/j.compositesa.2012.09.001

48 C. S. S. S. Lima, M. M. Conceição, F. L. H. H. Silva, E. E. Lima, L. S. Conrado et al., Appl. Energ., 102, $254 \quad$ (2013) https://doi.org/10.1016/j.apenergy.2012.09.061

49 L. Yang, M. Lu, S. Carl, J. A. Mayer, J. C. Cushman et al., Biomass. Bioenerg., 76, 43 (2015), https://doi.org/10.1016/j.biombioe.2015.03.004

50 K. R. Corbin, C. S. Byrt, S. Bauer, S. DeBolt, D. Chambers et al., PLoS One, 10, 1 (2015), doi: 10.1371/journal.pone.0135382

51 A. Altinisik, Y. Seki, S. Ertas, E. Akar, E. Bozacı et al., Fiber. Polym., 16, $370 \quad$ (2015), https://doi.org/10.1007/s12221-015-0370-9

52 A. E. O. Ben Sghaier, Y. Chaabouni, S. Msahli and F. Sakli, Ind. Crop. Prod., 36, 257 (2012), https://doi.org/10.1016/j.indcrop.2011.09.012

53 B. M. Cherian, A. L. Leão, S. F. de Souza, S. Thomas, L. A. Pothan et al., Carbohyd. Polym., 81, 720 https://doi.org/10.1016/j.carbpol.2010.03.046

54 A. Santos, F. Rodriguez, M. Gilarranz, D. Moreno and F. Garcia-Ochoa, Ind. Eng. Chem. Res., 36, 4114 (1997), https://doi.org/10.1021/ie9701940
55 R. B. Santos, E. A. Capanema, M. Y. Balakshin, H. M. Chang and H. Jameel, J. Agric. Food Chem., 60, 4923 (2012), doi: 10.1021/jf301276a

56 A. S. Singha and R. K. Rana, Carbohyd. Polym., 87, 500 (2012), doi: 10.1016/j.carbpol.2011.08.011.

57 J. J. Villaverde, J. Li, M. Ek, P. Ligero and A. De Vega, J. Agric. Food Chem., 57, 6262 (2009), doi: $10.1021 / \mathrm{jf} 900483 \mathrm{t}$.

58 H. M. Hernández-Hernández, J. J. Chanona-Pérez, G. Calderón-Domínguez, M. J. Perea-Flores, J. A. Mendoza-Pérez et al., Microsc. Microanal., 20, 1436 (2014), https://doi.org/10.1017/S1431927614012987

59 V. C. Coletta, C. A. Rezende, F. R. da Conceição, I. Polikarpov and F. E. G. Guimarães, Biotechnol. Biofuels, 6, 43 (2013), doi: 10.1186/1754-6834-6-43

60 K. Kavkler and A. Demšar, Spectrochim. Acta - A, 78, 740 (2011), doi: 10.1016/j.saa.2010.12.006

${ }^{61}$ U. P. Agarwal and S. A. Ralph, Appl. Spectrosc., 51, 1648 (1997), doi: 10.1366/0003702971939316

${ }^{62}$ U. P. Agarwal and R. S. Reiner, J. Raman Spectrosc., 40, 1527 (2009), doi: 10.1002/jrs.2294

63 U. P. Agarwal, J. D. McSweeny and S. A. Ralph, J. Wood Chem. Technol., 31, 324 (2011), DOI: $10.1080 / 02773813.2011 .562338$ 